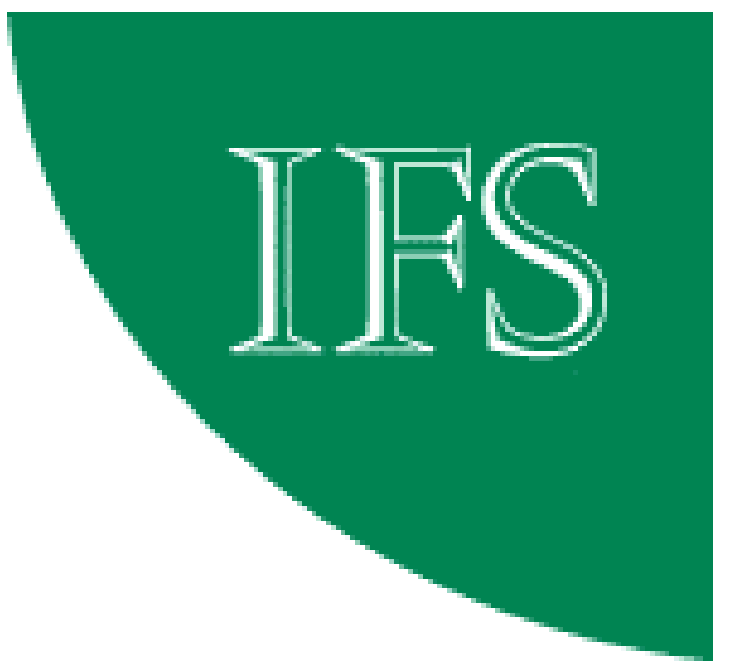

\title{
ILL HEALTH AND RETIREMENT IN BRITAIN: A PANEl DATA BASED ANALYSIS
}

\author{
Richard Disney \\ Carl Emmerson \\ Matthew Wakefield
}


3 March, 2003

\title{
Ill-health and retirement in Britain: A panel data-based analysis
}

\author{
Richard Disney ${ }^{*}$, Carl Emmerson ${ }^{\dagger}$ and Matthew Wakefield ${ }^{\dagger}$
}

\begin{abstract}
We examine the role of ill-health in retirement decisions in Britain, using the first eight waves of the British Household Panel Survey (1991-98). As self-reported health status is likely to be endogenous to the retirement decision, we instrument self-reported health by a constructed 'health stock' measure using a set of health indicator variables and personal characteristics, as suggested by Bound et al (1999). Using both linear and non-linear fixed effects estimators, we show that adverse individual health shocks are an important predictor of individual retirement behaviour. We compare the impact of our constructed health measure on economic activity with that arising from the use of other health variables in the data set. We also examine the impact of the 1995 reform of disability benefits on the retirement decision.
\end{abstract}

Key Words Ill health Retirement Disability insurance JEL classification H55 I12 J26

\section{Acknowledgements}

We are grateful to the Nuffield Foundation for funding the project: 'A study of health and the labour market behaviour of older workers', and to Sharon Witherspoon in particular. Cofunding was provided by the ESRC Centre for the Microeconomic Analysis of Public Policy (CPP). We thank Erich Battistin and Frank Windmeijer for valuable advice and comments, and participants at seminars at the Institute for Fiscal Studies, and the Universities of Newcastle, St Andrews and Strathclyde. The British Household Panel Survey data used in this paper were made available through the UK Data Archive, funded by the ESRC. The usual disclaimers apply.

\footnotetext{
* Institute for Fiscal Studies, London and University of Nottingham

$\dagger$ Institute for Fiscal Studies, London.
} 


\section{Executive Summary}

This paper examines the role of ill-health in retirement decisions in Britain, using the first eight waves of the British Household Panel Survey (1991-98). To tackle the problem that self-reported health status is likely to be endogenous to the retirement decision, a two-stage method, as suggested by Bound et al (1999), is adopted. The first stage is to construct a 'health stock' measure that is cleansed of the effects of reporting behaviour reflecting labour market participation. This measure is then introduced into a reduced form model of labour market (in)activity. At this latter stage, modelling how labour market transitions are related to time variation in health and other characteristics, helps to eliminate any unchanging person-specific association between characteristics and the decision to work.

The 'health-stock' measure is constructed by regressing self-reported health on a set of more objective health indicator variables and a set of other personal characteristics. Few personal characteristics, other than those related to health, are found to be significant in explaining self-assessed health. Many of the health indicators are significant in the model, and as expected having health problems is associated with reporting poor health.

The panel structure of the data set is exploited to estimate a non-linear 'fixedeffects' model that allows an exploration of how time variation in various characteristics relates to transitions out of (and in to) work. Deterioration in an individual's health is found to be strongly positively associated with movement out of work. Sensitivity analyses suggest that there may be some asymmetry between the respective effects of health deteriorations and improvements on transitions out of, and in to, work.

The final section briefly considers a reform to the public disability insurance programme in 1995, which both tightened formal eligibility conditions and reduced the economic incentives to retire via the disability insurance 'route'. No significant effects are found. This may reflect that there indeed were no effects (a result that is not incompatible with the aggregate data), or it may reflect the weakness of the test that could be constructed given the framework and data used. 


\section{Ill-health and retirement in Britain: A panel data-based analysis}

\section{Introduction}

The number of people on disability benefits more than doubled between the late 1970s and the middle of the 1990s in Britain. 'Ill health' is a major reason for retirement among men, especially for men without access to an occupation pension (Tanner, 1998, Table 7). Indeed 'own ill health' is the most commonly cited reason for retirement among both men and women in the early 1990s (Disney, Grundy and Johnson, 1997, Table 2.19). Similar trends have been observed in other countries such as the Netherlands and the United States (Bound and Burkhauser, 1999).

There is a strong correlation between observing a person not working and their self-reported poor health status, but this may give a misleading impression of the impact of health status on retirement. First, individuals who are inactive often have an incentive, for self-esteem if nothing else, to report worse-than-actual health. Second, differences in reported self-assessed health are large, even for individuals in identical labour market states - individual heterogeneity is important. Third, individuals with genuine ill-health may never have worked, so they cannot be observed 'retiring'. Fourth, genuine ill-health may impact on other labour market attributes of the worker (for example, the wage they earn - see Meghir and Whitehouse, 1997) which implies that there are both income and substitution effects on labour supply arising from shocks to the worker's health status. Finally, the health stock may be endogenous to the labour market state of the individual (Kerkhofs, Lindeboom and Theeuwes, 1999).

The potential measurement error and endogeneity of self-reported health status has led some writers to reject the use of self-reported health status (Myers, 1982) even though it has been, and continues to be, commonly used in this field for want of better measures. ${ }^{1}$ A further problem is that, in the UK at least, for those individuals with no occupational pension rights, disability benefits are the only 'route' into early retirement through the social security programme, since the social security pension cannot be

\footnotetext{
1 For a survey of US evidence that uses self-reported measures, see Quinn, Burkhauser and Myers (1990). There are relatively few studies of retirement behaviour in the United Kingdom. Zabalza, Pissarides and Barton (1980) use self-reported 'poor health', Meghir and Whitehouse (1997) use selfreported 'health problems' as their proxy for ill health and Miniaci and Stancanelli (1998) use 'ill health as a reason for leaving last job' in modelling the ill health-retirement 'route'. Blundell, Meghir and Smith (2002) is described below.
} 
received before the state pension age (currently 65 for men and 60 for women). Consequently, there is an inducement for early retirees to utilise the ill-health route and their self-assessed health status will correlate with preferences for early retirement (Blundell and Johnson, 1998). ${ }^{2}$

For the researcher interested in the link between ill health and retirement, one obvious strategy is to substitute more objective measures of ill health (if available) for self-reported health status in the model 'explaining' retirement. ${ }^{3}$ Some studies have argued for the intrinsic superiority of this approach, since it eliminates the errors-invariables and biases arising from the subjective health measure (many such studies are cited in Quinn, Burkhauser and Myers, 1990). But, Bound (1991) points out, we cannot be sure that such proxies are any better predictors of (in)activity than self-reported health status, as the researcher implicitly thereby assumes some link between work status and these other health measures. ${ }^{4}$ Such a strategy does not eliminate the errors-in-variables problem but replaces it with a similar problem on a proxy variable, and may thereby lose any additional information on the 'true' association between health and behaviour that might be intrinsic to the self-reported 'subjective' measure. ${ }^{5}$

Another pertinent suggestion, explored by Anderson, Burkhauser and Quinn (1986) and Bound, Schoenbaum, Stinebrickner and Waidmann (1999) (hereafter Bound et a) is that changes in labour market status e.g. 'retirement' (whether permanent or temporary) should be associated with 'shocks' to the individual's underlying 'health stock'. Bound et als strategy is to construct a latent health stock or index of health for each individual as a function of personal characteristics and health indicators. This constructed variable can be used to instrument self-reported health in a panel data model of economic activity in order to explore the relationship between time variation in health and changes in work status (see also Stern, 1989). Modelling health 'shocks', it can be argued, eliminates any person-specific association between characteristics and labour

\footnotetext{
${ }^{2}$ Of course, receipt of disability benefit is also conditioned on various 'objective' health assessments and work capability tests. These have changed over time - for further discussion see Disney, Emmerson, Smith and Smith (2002).

3 This 'objective' measures may also be self-reported, or externally assessed by the interviewer or by some form of medical examination. In the UK context again, Blundell, Meghir and Smith (2002), in their model of the impact of pension incentives on retirement, use a disability 'severity score' calculated from various 'objective' measures of self-reported disability, and also estimate an auxiliary reduced form probit for receipt of Invalidity Benefit.

${ }^{4}$ For example, construction of a disability 'score' such as the well known Disability Living Index may not primarily be motivated by attempts to measure the employment capacity of the individual.
} 
market outcomes (such as preferences for work, or longstanding disability), whilst proxying self-reported health status by time-varying health and personal characteristics should ameliorate any reporting bias in the former.

This paper follows the strategy suggested by these authors. It exploits the panel element of the data set to construct individual 'health stocks', and uses time variation in these 'stocks' as an explanatory variable in reduced form models of labour market (in)activity amongst older people. These labour market outcomes are modelled using linear and non-linear fixed effects estimator. We also experimented with other indicators of health-related retirement, including applying a similar modelling technique to a question concerning work-limiting health, as well as direct input of the more objective health measures that we describe shortly. We test for symmetry in the relationship of labour market transitions to improving and worsening health. We do not, in this paper, explore the 'feedback' of labour market activity or inactivity on the evolving health stock.

We also examine the regime change in 1995, which replaced Invalidity Benefit by Incapacity Benefit, tightened some eligibility conditions and cut real benefits. In principle, this policy change strengthened the link between 'true' work-related disability and inactivity, so that we might observe a change in the health stock-economic activity relationship around this time.

The structure of the paper is as follows. Section 2 describes the construction of our health stock variable. Section 3 uses this variable as an instrument for health status in a reduced form labour market (in)activity model. Section 4 describes our sensitivity analysis to alternative health measures, asymmetries in the health-economic activity relationship, and possible omitted variables. It also reports our attempts to model the change in the disability benefit regime. Section 5 concludes.

\section{Modelling the individual's health stock}

\subsection{Data and modelling issues}

To construct an individual's underlying 'health stock', we follow Bound et al (1999). Assume that the $i^{\text {th }}$ individual's health at time $t$ is determined by a linear combination of exogenous personal characteristics (such as age and education) $x_{i \text {, a }}$

\footnotetext{
5 There is some evidence, for example, that self-reported health status is an additional predictor of individual mortality after controlling for observables (Kaplan and Camacho, 1983; Wannamethe and Shaper, 1991).
} 
vector of detailed personal health indicators (such as functional limitations) $z_{i t}$ and unobservables $v_{i t}$ uncorrelated with $x_{i t}$ and $z_{i r}$ We allow the impact of these characteristics to vary over time. Denote this (unobserved) health state as $\eta_{i t}$ So:

$$
\eta_{i t}=x_{i t}^{\prime} \beta_{t}+z_{i t}^{\prime} \gamma_{t}+v_{i t}
$$

Although this health state is not observed, a self-reported health status is observed in our data, as a categorical variable with five 'states': 'excellent', 'good', 'fair', 'poor' and 'very poor' (the exact form of the question is discussed below). Denote this categorical variable as $h_{i \text { r }}$. The latent counterpart to $h_{i}$, which is denoted by $b^{*}{ }_{i p}$ is a simple function of $\eta_{i t}$ and a term reflecting reporting error:

$$
h^{*}{ }_{i t}=\eta_{i t}+\varepsilon_{i t}
$$

Crucially, we assume that $\varepsilon_{i t}$ is uncorrelated with $v_{i t}$ Reporting error may well be correlated with the state in which the individual is located. By using this instrumental variable-type procedure, we are assuming that the errors are uncorrelated with those arising when reporting specific health limitations. Thus we write:

$$
\begin{aligned}
& h^{*}{ }_{i t}=x_{i t}^{\prime} \beta_{t}+z_{i t}^{\prime} \gamma_{t}+\left[v_{i t}+\varepsilon_{i t}\right] \\
& h^{*}{ }_{i t}=x_{i t}^{\prime} \beta_{t}+z_{i t}^{\prime} \gamma_{t}+u_{i t}
\end{aligned}
$$

Assuming that $u_{i t}$ is normally distributed, equation (3) can be estimated as an ordered probit.

To reiterate, therefore: we construct this time varying individual 'health stock' to strip the health term in the labour force participation equation of possible endogeneity of response. Using self-reported health status, $h_{i p}$ as a proxy for $\eta_{i t}$ directly will be biased if the reporting error term in equation (2) is correlated with terms in the labour force participation equation that we estimate in the next section. However, simply entering the $\mathfrak{z}_{i t}$ vector in equation (1) directly into a labour force participation equation will likely induce errors-in-variables biases, because more specific health factors, even if accurately reported, may not perfectly predict current capacity to work. ${ }^{6}$ Using the latent variable model in equation (3), Bound et al (1999) argue, is a standard measure of dealing with these problems, by using a proxy with error to instrument an endogenous and errorridden variable such as $b^{*}$ (see also Griliches (1974)).

\footnotetext{
${ }^{6}$ Bound (1991) illustrates these likely outcomes concerning $b^{*}$ and the use of 'objective factors', formally: see ibid pp.110-114.
} 
The data used in the analysis are drawn from the first eight waves of the British Household Panel Survey (BHPS), 1991-98. This survey provides a sample that was selected to be representative of the population of England, Wales and Scotland (south of the Caledonian Canal). Since we are interested in the retirement behaviour of older workers we use a subsample of people aged 50 to 64 in 1991 and who by the end of our sample period have reached ages 57 to 71 . This selection by age, coupled with the requirement that we observe certain variables (particularly work status and health) leaves us with a sample of 1,712 individuals in 1991, reduced to 1,253 by 1998 .

One advantage of using this data is that it is a panel that allows us to track individuals over a relatively long period of time: our eight year panel is significantly longer than that available to Bound et al (1999), for example. The BHPS also records a rich set of characteristics for individuals in the sample. In what follows we use data on educational achievement, family composition, region of residence and a derived variable on housing wealth, ${ }^{8}$ as the components of the $x_{i t}$ vector, and the many measures of individual health that are contained in the survey as the components of the $\mathfrak{r}_{i t}$ vector.

What measures of health status are contained in the data set: i.e. the $z_{i t}$ vector in equation (1)? Aside from recording whether or not the individual is registered disabled these come in two sets, the first recording whether or not individuals say that they have certain health problems and disabilities and the second recording whether or not individuals feel that their health limits their ability to perform certain daily activities. The health problems and disabilities that individuals are asked about are: problems with arms, legs, hands, feet, back or neck; difficulty seeing; difficulty hearing; skin conditions and allergies; chest or breathing problems including asthma and bronchitis; heart problems and blood pressure or circulation problems; stomach, liver, kidney or digestive problems; diabetes; anxiety, depression or bad nerves; alcohol or drug related problems; epilepsy; migraine or frequent headaches; other health problems. After being asked "does your health limit your daily activities compared to most people of your age?", the specific activities that BHPS respondents are asked about are: doing the housework; climbing stairs; dressing oneself; walking for at least ten minutes.?

\footnotetext{
${ }^{7}$ The question relating to health status changed in the BHPS in 1999.

${ }^{8}$ Our thanks to Andrew Henley at University College, Aberystwyth for providing the results of his programme that models housing equity in the BHPS.

9 The BHPS also contains a series of questions that contribute to a constructed index of "subjective well being". These questions ask things like whether or not people feel that recently their concentration has been good, and whether or not they feel that recently they "have been playing a useful part in
} 
As explained above, the specific indicators of health are used to cleanse the more subjective general assessment of health of response patterns that, we argued, might be correlated with work status. The general health measure $h_{i t}$ is a response to the question: "Please think back over the last 12 months about how your health has been. Compared to other people of your own age, would you say that your health on the whole has been: excellent; good; fair; poor; very poor; don't know" (our italics). ${ }^{10}$

It is noteworthy that the self-reported health status variable that we use is derived from a question that specifically asks respondents to compare their own health to that of other people of their own age. The likely expected decline in health status as the panel of respondents ages should not therefore be picked up by the variable. It follows that, in our retirement model, we should interpret a significant coefficient on our constructed health variable as indicating that individual-specific variations in health have an impact on labour market activity. The cumulative effect on retirement decisions of the general deterioration of health with age should be picked up through other variables in the model, in particular by the age terms.

Notwithstanding the relative nature of the health question, there does seem to be a general decline in self-assessed health relative to the cohort. This is seen from year-onyear comparisons of the data. The overall effect can be seen by comparing the first and last years of data, presented in Table 1, where we differentiate between the whole sample in each year, and those who were present in both years: ${ }^{11}$

\section{Table 1 here}

This, of course, provides another reason for being cautious about simply using the self-reported overall health measure in an analysis of economic (in)activity. The average decline in self-reported health relative to the cohort may arise from a change in self-perception, or a change in the comparison group implicitly used by the respondent

things". In total there are twelve such questions, but after some experimentation we decided not to use these variables as asking how people feel about themselves may be more subjective than the sets of questions about health problems and limitations on daily activities.

${ }^{10}$ Contoyiannis and Rice (2001) use this exact variable in their analysis of the impact of health on wages. When they use panel IV estimators, the impact of self-reported health status is not significant (ibid Tables 3 and 4) suggesting that measurement error (heterogeneity) dominates. Note that we allow for person specific effects at the second stage of our estimation procedure.

11 The numbers decline due to sample attrition over the period of the panel, either through death or non-response. Note that biases due to the association of poor health and mortality should lead to an overestimate of the average health of the ageing cohort since subsequent responses are conditioned on survival. The smaller number in the second set of cells arises because some individuals observed in 1998 failed to respond to all the health questions in 1991. 
(who may be, for example, assessing only those people of similar ages who are still economically active - although our sample includes both the active and the inactive).

\subsection{Estimation}

We now estimate the model for the latent 'health stock'. Using as the dependent variable the categorical variable described above, Table 2 depicts the ordered probit underlying equation (3) for 1991.

\section{Table 2 bere}

Looking at the sample characteristics, the first column of the table reveals that there are slightly more women than men in the initial sample. Almost four fifths of respondents are in a couple rather than single. The majority are owner occupiers, and almost $40 \%$ own outright. Housing equity is defined in thousand pounds. Almost half the sample have no educational qualifications, although there is wide variation. Of the sample, only $6 \%$ are registered disabled but significant proportions of the sample report having difficulties or health problems, notably with arms/legs/hands, lung or heart problems.

Examining the parameter estimates, few personal characteristics, other than those related to health, are significant in explaining self-assessed health. Individuals in a couple and with higher housing equity are likely to report 'better' categorical health status; those without qualifications worse. The education variables are jointly significant with more highly educated people in general reporting better health. The regional dummies are jointly insignificant in explaining self-reported health status, although previous studies of the incidence of disability benefit receipt (such as Disney and Webb, 1991) show strong regional disparities, suggesting that regional labour market differences might be important in explaining economic inactivity. However it should be borne in mind again that the question invites the respondent to compare their health status with people of a similar age, which may be geographically-specific.

In contrast to personal characteristics, and as expected, many of the health measures are individually significant at the one or five percent levels, and tests of joint significance show that the measures of functional limitations are very significant when considered together, as are the variables recording health conditions and problems. 
Among these variables only 'getting dressed', 'registered disabled' and 'hearing difficulties' have an insignificant impact on self-reported health status.

It is would be desirable to provide some interpretation of the coefficients as 'marginal effects'. But it is well known that it is difficult to interpret the coefficients in an ordered discrete choice model like this ordered probit in this way. ${ }^{12} \mathrm{~A}$ positive coefficient unambiguously means that an increase in the variable concerned will decrease the probability with which an individual is predicted to be in the lowest health category (very poor) and increase the probability with which they are predicted to be in excellent health, and vice versa. So the negative sign on coefficients on all of the health variables are (with the one exception of 'hearing difficulties') as we would expect. To get a feel for parameter estimates: if we take a representative individual who has the average (mean) values for characteristics measured by continuous variables and is assigned values of the dummy variable characteristics that are the most common in the data, then the predicted probability of being in excellent health if the person has no chest or breathing problems is 0.30 . If they have chest problems it is only 0.07 .

The predicted values of the index for each individual from this equation constitute the individual 'health stocks' in 1991. We normalise these to give an absolute deviation of the individual's health stock from the cohort average for each year. Normalising in this way avoids the need to make any further assumptions to identify the constant in each separate ordered probit. These predicted individual 'health stocks' for each successive year are then updated in the light of new information on the $\gamma_{i t}$ and $x_{i t}$ vectors contained in the data. We update by running a new ordered probit for each year on same set of independent variables that are used in the first year. We predict the health stock index and normalise by subtracting the year specific mean, in the same way as described for the 1991 data. In this fashion, we construct an evolving health stock for each individual (relative to the year-on-year average for the sample) in the data set over the period 1991-98. ${ }^{13}$ These are the latent health stock measures that will be introduced into the reduced form equations describing the evolution of each individual's economic (in)activity. The descriptive statistics for these constructed health stocks, which are useful

\footnotetext{
${ }^{12}$ See, Greene (2000, p.876ff.) or Wooldridge (2002, p. 504ff.).

13 Results of the ordered probits for the years 1992-1998 can be obtained from the authors on request. Qualitatively they are similar to the results for 1991.
} 
for interpreting coefficients in the models that follow, appear in an Appendix to the paper.

\section{The impact of health on 'retirement'}

\subsection{Theory}

The economic theory underlying the relationship between ill-health and retirement is standard (for example, Lazear, 1986). Agents have preferences over current and future leisure, with the value of current and future leisure depending, inter alia, on current and expected states of health. Agents form expectations over future states of health. They maximise utility subject to the lifetime budget constraint, and standard dynamic optimisation conditions determine choice of retirement date, R*. Shocks to income, preferences, or both, will affect $\mathrm{R}^{*}$. There are various models of how people solve this optimisation problem. ${ }^{14}$ There may be some institutional constraints that limit choice of $\mathrm{R}^{*}$ but, in the United Kingdom, these are relatively few - participants can annuitise a private pension from age 50 and can both receive pensions and continue to work (for another employer) for as long as they like without a retirement test, at least since the abolition of the Earnings Rule in 1989 (Disney and Smith, 2002).

Poorer health status, ceteris paribus, will reduce the probability of continued work for several reasons. First, poorer health may raise the current disutility of work. Second, poorer health reduces the return from work if there is a relationship between poor health and low wages. Third, poor health may entitle the individual to non-wage income, such as disability benefits, which is contingent on not being in work. The only counteracting principle is if poor health raises consumption requirements (for example, the cost of health treatment) and requires greater income than can be provided through the disability insurance programme. On the other hand, if poorer health is associated with lower life expectancy, the annualised consumption available from existing wealth is raised which might induce earlier retirement.

In this framework, however, it is important to differentiate 'levels' of health from health 'shocks'. As mentioned in the introduction, longstanding poor health may be

\footnotetext{
14 For example, individuals may notionally evaluate the utility from retirement now against all future prospective utility streams, including returns to work, as in a dynamic programming problem, or else evaluate retirement now against the highest valued stream from future retirement, assuming retirement is an absorbing state, as in the 'option value' model.
} 
associated with a lower lifetime probability of work and thus, in extreme cases, retirement will not be observed simply because the individual never worked. Moreover, a slow decline in health status later in the working life may be anticipated and already incorporated into the optimal retirement strategy. Thus a measure of the time variation in the individual's health 'stock', as constructed here, estimated over those that change status between activity and inactivity, should provide an appropriate test of the standard model.

\subsection{Estimation}

We now examine the role of the constructed health stock in a reduced form model of retirement. Here, we estimate a simplified version of the underlying model as described in equation (4) of the previous section. In the next section, a sensitivity analysis to the measure of the health stock is considered, as well as the impact of the 1995 change to the disability insurance regime.

Since only the outcome is observed, a discrete choice model that incorporates dynamics (fixed effects) is appropriate. The fixed effects discrete choice model is:

$$
\begin{aligned}
& l f *_{i t}=\alpha_{i}+\eta_{i t} \lambda+x_{i t}^{\prime} \beta+\varepsilon_{i t}, \quad i=1 \ldots . n, t=1 \ldots T \\
& l f_{i t}=1 \text { if } l f_{i t}^{*}>0, \text { and } 0 \text { otherwise }
\end{aligned}
$$

where $l f_{i t}^{*}$ is the latent variable that indexes the probability of participation of individual i at time $t$, here defined as whether the individual reports that they are currently working (including self-employment), $\eta_{i t}$ is the unobserved health state, $x_{i t}^{\prime}$ is a vector of other characteristics and $\alpha_{i}$ is the individual fixed effect. The fixed effects (conditional) logit model is written in general as:

$$
\operatorname{Pr}\left(l f_{i t}=1 \mid\left(x_{i t}, \eta_{i t}\right)=\frac{e^{a_{i}+\eta_{i t} \lambda+x_{i t}^{\prime} \beta}}{1+e^{a_{i}+\eta_{i t} \lambda+x_{i t}^{\prime} \beta}} \quad \quad\right. \text { (missing bracket here) }
$$

Chamberlain (1980) notes that the conditional likelihood function is free of the incidental ('fixed effect') parameters, $\alpha_{i}$. This is because a contribution to the likelihood only arises from those groups of observations (of a given individual over time, say) that are not always zero or one - in this case, those who transit 'states' between economic activity and inactivity. 
The vector of explanatory variables for economic activity status comprises $\hat{h}_{i t}$, which is the predicted value of the underlying health 'stock' $\eta_{i t}$ for the individual, relative to the average for each year, obtained from estimating equation (3) as described previously, and a vector of time-varying individual characteristics. Variable definitions are as follows:

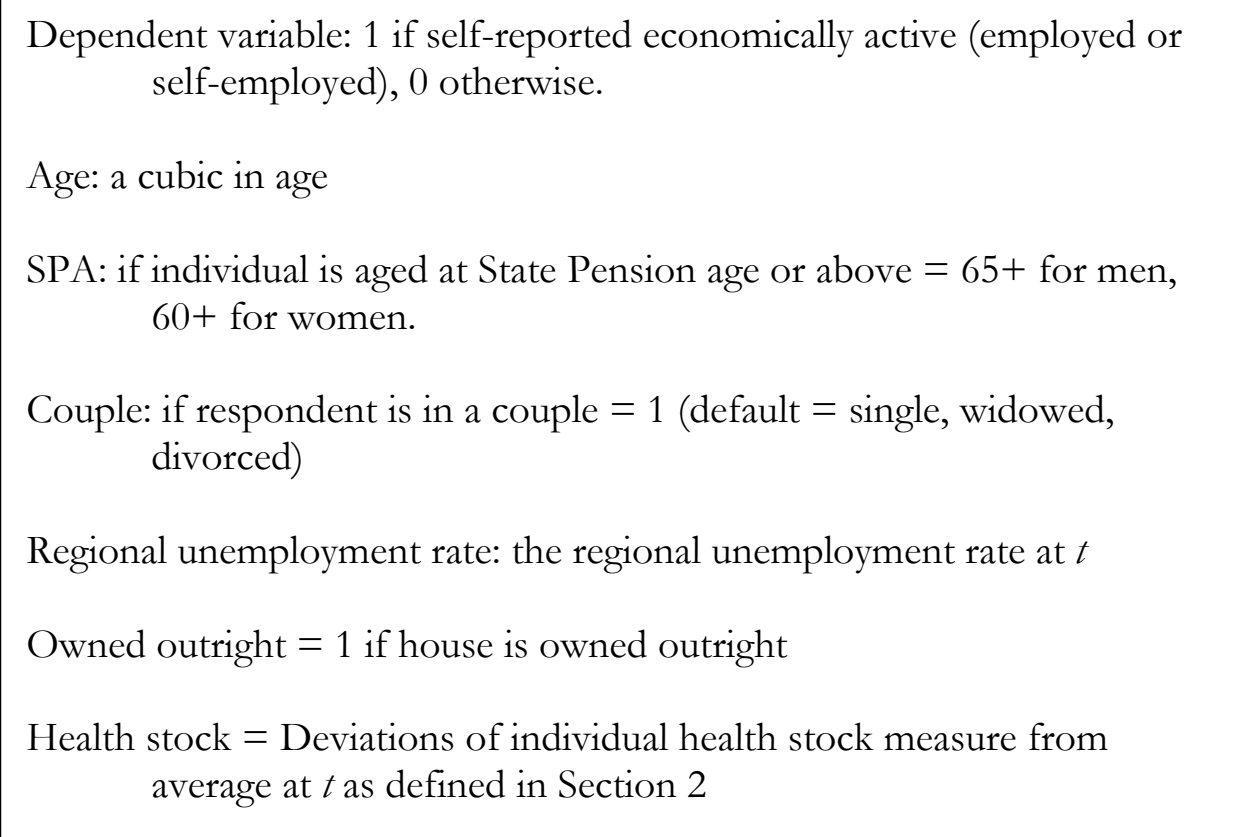

Table 3 illustrates the results of this exercise.

Table 3 here

Economic activity is related to age via a cubic and a dummy representing whether the individual is over state pension age or not. ${ }^{15}$ Individuals in couples are less likely to work, as are individuals who own their home outright (although neither is significant at the $5 \%$ level in the preferred specification). ${ }^{16}$ We interpret these characteristics as reducing the consumption requirements of households, and thus the probability of working. As would be expected, higher local unemployment rates are associated with a lower probability of economic activity. Of most interest, however, is the coefficient on

\footnotetext{
15 Since, since strictly speaking, health measures are relative to the cohort, the age effects should also be proxying the gradual cohort deterioration in health status, but the relationship between age and activity is not linear. Moreover, as shown in Table 1, individuals do not appear wholly to interpret the categorical health status question as a measure relative to their entire age group.

${ }^{16}$ In the fixed effects logit, we can also interpret this as saying that becoming married or cohabiting, and paying off a mortgage, increases the probability of retirement. This is also the interpretation to be put on the coefficients in the linear fixed effects model.
} 
the individual's relative health status, which is strongly positively associated with economic activity (a higher value indicating better health). This is an important result, bearing in mind that we are using a constructed variable proxying an assumed underlying health stock. Moreover, by focussing on individuals who change state, we have established the link between changing health status and retirement, as opposed simply to underlying (in)activity.

The other specifications in Table 3 are for comparison. A simple logit without fixed effects but augmented with standard time invariant characteristics (column 2) gives a much stronger relationship of activity with health status (and correspondingly weaker age effects). These effects are identified off all individuals, including those who are active and inactive over the whole period, rather than simply those who transit states. The coefficients derived from the standard logit are mostly significantly different from those derived from the fixed effects logit and we prefer the latter since most other studies suggest that individual fixed effects are important in modelling retirement (as in Meghir and Whitehouse, 1997, and Blundell, Meghir and Smith, 2002).

Column 3 provides the standard linear fixed effects estimator. This identifies effects off time-varying characteristics - such as marital status or home ownership - of all individuals. It gives similar results to column 1, and the coefficients are more easily interpretable than the conditional logit. However the linear model is an inappropriate choice when the variable of interest is dichotomous, as in the present case. Thus we prefer the specification in column 1 .

\section{Sensitivity Analysis, and the 1995 reform}

\subsection{Sensitivity to bealth measures and other variables}

We focus here on the sensitivity of the results to alternative specifications, most particularly to using more specific measures of health status. We examine also whether the response of state transitions is symmetrical, especially in relation to the health variable. Finally, we look for evidence of a change in retirement behaviour as a result of the 1995 reform to the public disability insurance programme, which reduced eligibility for disability benefits and reduced the financial incentives to claim disability insurance benefit relative to other insurance benefits. Throughout the analysis, we evaluate alternatives relative to the results for the fixed effect logit in column (1) of Table 3. 
First, we examine the inclusion of additional conditioning variables. We examined whether the impact of the health stock proxy on the probability of economic activity is different for men and women, by including an additional interaction of 'health stock' with a gender dummy. The inclusion of the extra variable is, however, easily rejected $\left(\chi^{2}=1.85\right.$, Prob $\left.>\chi^{2}=0.17\right)$. We also examined whether partner's health is an important predictor of changes in labour market status. Although there is the possibility that partner's health status may also suffer from reporting bias, missing values mean that we would have to reduce sample size considerably if we were to follow the same procedure to construct a health stock for both the respondent and partner. ${ }^{17}$ Even using the categorical self-reported variable for the partner introduces a number of missing observations. Nevertheless, including the partner's self-reported status (classified by five possible outcomes as before) plus a dummy for missing values for partner's health was insignificant (using a Likelihood Ratio test, $\chi^{2}=0.46$, Prob $>\chi^{2}=0.80$ )

Second, we tested whether the participation response of individuals to health shocks is symmetric - that is, whether improvements in health are associated with transitions into work in the same way that deteriorations are linked to movements out of work. Alternatively there may be a 'ratchet' effect such that after an individual's poor health has caused exit from work, it requires health to recover beyond the threshold that induced exit in order to encourage new efforts to seek work. ${ }^{18}$ However, given that the sample variable used, and the 'health stock' derived from it, measures an individual's health relative to that of other people of a similar age, it is misleading to utilise it to evaluate the direction of change in that individual's health status: a measured improvement may reflect that the health of the individual concerned has deteriorated by less than the average change across the whole sample. So, to carry out a test of symmetry, we utilised another variable in the data set, derived from the response to the question: 'Does your health limit the type of work or amount of work you can do?' [YES/NO] Responses to this variable are of course likely to be strongly endogenous to labour market status, and it is of some interest to see whether our instrumental variable-type technique gives similar results on this variable. We interpret responding negatively to this question as reporting being in 'good health'. We then use the same variable set as in

\footnotetext{
${ }^{17}$ This is because many of the individuals in our sample have a partner who is not in the cohort used for this analysis.

18 Thus, if retirement is always an 'absorbing state', then deteriorations in health will lead to retirement but improvements in health will not induce a return to work. In our data, there are roughly 3 times as many
} 
Table 2 in order to obtain derived individual year-specific predictions of the probability of responding negatively to this question (results are available on request from the authors). Unlike in the ordered probit used previously, there is just one probability of this kind that can be predicted from this standard probit. Further, in this case an increase in this probability can be interpreted as meaning that health has improved and become less of a constraint on work. The predicted probabilities are inserted in the labour market (in)activity equation in the same way as was our more detailed 'health stock' measure.

The results using this new predicted variable No health limit on work, analogous to Table 3, are contained in Table 4. Results are similar, but there is one additional variable. Since the probability of health affecting work is now measured as an 'absolute' probability, we introduce an interactive dummy capturing whether predicted health has improved or worsened. ${ }^{19}$ The term Symmetric health impact is this dummy multiplied by the predicted health measure where the dummy takes the value 1 when the health measure has improved relative to the previous year. By adding this additional term, we have an indirect test of a positive 'ratchet effect' of ill health on the retirement probability. A significant negative coefficient on the interacted health term suggests that an improvement in health has a weaker impact on the probability of transiting from inactivity to activity than the reverse. And this is the result obtained, significant at between $1 \%$ and $3 \%$ depending on specification. Note, however, that the coefficient does not fully cancel out the health effect - the impact of improving health on the transition to economic activity is weaker, but present.

\section{Table 4 bere}

We also investigate further sensitivity of the results to the measure of the health stock. As argued in Section 1, economic activity should be strongly correlated with subjective, work-related, measures of health status in part due to reporting bias. On the other hand, specific indicators of disability may have a weaker correlation with economic activity simply because there some of these disabilities may have relatively little impact on capacity to work.

Table 5 provides coefficients and standard errors for our baseline specification of the 'health stock' variable and for directly input measures of health difficulties and

\footnotetext{
moves 'out' of economic activity as there are 'in'; moreover these moves 'in' are concentrated among a smaller number of multiple movers.

${ }^{19}$ Note that we require at least two observations to observe this change, so that the first observation of each respondent is absent. This is why the sample size is smaller in Table 4 than Table 3.
} 
functional limitations without the instrumental variable-type approach used in Tables 3 and 4. Column 1 gives the coefficient and standard error from the calculated measure used in Table 3, as a benchmark.

\section{Table 5 bere}

Column 2 provides the coefficient on two count variables, which count up the number of difficulties in basic physical activities $(j=1$ to 4$)$ and the number of reported health problems ( $n=1$ to 13), as well as whether the individual is registered disabled, as reported by the individual. A higher count in each case should be associated with a greater number of functional limitations or incapacities and therefore with a greater probability of retirement, so these can be regarded as crude self-reported 'disability indices'. It will be noted that the sign on the number of self-reported difficulties and, not surprisingly, being registered disabled, is negative. This is also true with the count of up to 13 'health problems' but the latter, unlike the other variables, is not statistically significant.

We can see why the count variable is insignificant in Column 3, which includes separately all the self-reported difficulties and health limitations that were utilised to construct the health stock measure in Table 3 and the count variables in Column 2 of Table 5. A negative sign is associated with a greater probability of inactivity. The first striking feature, which underpins the result in column 2 , is that many self-reported health difficulties have the 'wrong' sign, in the sense that they are associated with economic activity, rather than predicting inactivity.

By sequential restrictions, we can eliminate the insignificant regressors to arrive at a parsimonious specification of a model that enters the $z_{i t}$ vector directly. This is contained in column 4 of Table 5 . In so doing, it can be seen that the only 'health difficulty' that survives this simplifying process - reporting a diabetic condition - is positively associated with work status. ${ }^{20}$ The other remaining variables: self-reported difficulties in walking and getting dressed, and registered disabled are all likely to be associated with severer disability.

Overall, columns 2 to 4 suggest that the strategy of entering specific health problems and self-reported difficulties in basic physical activities into the retirement model is not particularly successful. It is of course possible that a proper objective (i.e. 
measured by an impartial third party) indicator of functional limitations and/or incapacity is required to pin down the exact relationship between measures of physical and mental ill-health and retirement behaviour. However, the results suggest that the best way to introduce these more objective factors, given the data available, is through the two-stage process by which the combination of these, and other, factors generate underlying health stocks, measures of which are the key to explaining the link between health status and economic activity.

\subsection{Reform of the disability insurance programme}

In 1995, the government introduced a number of significant reforms to the public disability insurance programme. Invalidity Benefit (IVB), the main insurance benefit for those with chronic ill-health and disabilities, was to be phased out and replaced by Incapacity Benefit (ICB). ICB is not available to individuals over state pension age (men, 65 and women, 60) unlike IVB, which was available until men and women were respectively 70 and 65. As existing claimants reached 70 and 65, therefore, claims to IVB above state pension age would phase out. The reason that individuals might prefer to be on Invalidity Benefit rather the basic state retirement pension at state pension age was that the former was not liable to income tax, unlike the basic state pension. ICB is treated as taxable income. Finally, eligibility conditions to be accepted onto disability insurance were tightened up. Full details can be obtained in Disney et al (2003). The whole policy package was designed to arrest the rise in numbers of disability insurance recipients that had occurred since the 1970s, especially among older men.

Figure 1 illustrates the trends in receipt of disability insurance benefits among older age groups, both men and women, from the early 1980s. After 1995, the number of male claimants falls sharply, but it is apparent that this is almost wholly due to phasing out claims in the age group above state pension age $(65+)$. There is, however, a stabilisation in numbers for the age groups just below state pension age, relative to the rapid increase of the previous decade. ${ }^{21}$ For women, in contrast, it is seems clear that the

\footnotetext{
${ }^{20}$ In this sample, almost all those reporting a diabetic condition are working at the start of the period, which is why the coefficient appears so large.

21 One surmise is that the rapid rise in claimant numbers in the late 1980s is related to another institutional change - namely, government measures to target the long-term unemployed such as Restart. Circumstantial evidence suggests that Restart led to the transfer of significant number of unemployed claimants on to Invalidity Benefit. In which case, tapering out Restart, combined with the 1995 Act, may have led to a reversion to the earlier, slower, trend growth in claimant numbers. However this surmise requires further analysis.
} 
1995 reform did nothing to abate the rise in the number of disability insurance claimants for those below state pension age.

Figure 1 here

In principle, the object of such a reform is to change the link between ill-health and retirement. The number of individuals retiring on grounds of ill-health should diminish, as a result of the tightening of eligibility conditions. Whether a priori this reduces the total number of retirements is unclear, as the reform changes the economic incentives to retire across different retirement 'routes'. There are at least two implicit hypotheses that can tested in the present context. The first is that the 1995 legislation discouraged premature retirement (i.e. before state pension age). The second is that the link between retirement and ill-health was tightened as a result of the 1995 legislation so that, post-1995, the probability of a 'shock' of given intensity being associated with illhealth has changed. This can be thought of as raising the threshold at which a health shock precipitates a change in the economic status of the individual. It should be borne in mind from Figure 1, that, apart from the exclusion of individuals post-state pension age, there is no evidence of a change in trend among women, and only evidence of a slowing down in the increase in numbers of disability benefit recipients among men. The likelihood of a 'big' effect of the 1995 Act is going to be limited in our analysis, even if we have an appropriate model and the correct indicators of the health-disability insurance link.

To model the legislation we introduce two further variables into the basic retirement model. The basic hypothesis is that a given health shock will be associated with different behaviour after the tightening of eligibility requirements and reduced economic incentives post-1995. The first variable is a dummy variable that describes whether the individual is in the post-1995 Incapacity Benefit system, which requires that the individual is below state pension age after 1995 and not already in a spell of Invalidity Benefit. Since such individuals are no longer able to receive tax free Invalidity Benefit after state pension age, the present value of retiring through the disability 'route' is reduced. If eligibility conditions were effectively tightened, then people would also find it more difficult to move from work onto disability benefits after the reform. Our basic hypothesis therefore is that some people might stay in work longer in the new regime. The variable eligible ICB characterises this group of individuals. The second variable interacts this dummy with the calculated health stock, which we denote as 
hstock*eligible ICB. The interpretation here is that the 1995 reform raised the threshold 'shock' to health required to enter the ICB regime, thus changing the health stock-retirement relationship.

Table 6 presents the result for the two fixed effect specifications in Table 3, for the relevant variables: hstock, spa (state pension age or above), eligible ICB and hstock*eligible ICB (coefficients for the other controls are not reported here). As before, the health stock and state pension age variables are significant. The interaction between health stock and the post-1995 regime (hstock* eligible icb) is insignificant, suggesting that there may be no evidence of a break in the relationship between changes in the health stock and economic activity after 1995. The variable proxying eligibility post-1995 (eligible ICB) is also positive but insignificant with bootstrapped standard errors. A test of the joint exclusion restriction for both additional variables is not rejected. These weak results may reflect either a weak, or indeed no, relationship, or the difficulty of finding suitable proxies for the 1995 reform within the existing modelling framework.

\section{Table 6 here}

\section{Conclusion}

This paper represents one of the first attempts to examine the impact of ill-health on retirement in some detail in the United Kingdom, using the British Household Panel Survey. The focus of the paper is on the nature of health measures that are utilised in reduced form retirement models of the type described here. It argues that reporting bias is intrinsic to self-reported measures of general health (especially, in questions that explicitly link health to economic activity status), but that there is a lack of 'fit' between objective measures of disability and functional limitations on the one hand and health as it relates to economic activity on the other. We therefore follow the approach of Bound et al (1999) in constructing an underlying 'health stock' of the individual, and in treating temporal variations in this measure as proxying individual-specific 'health shocks' that affect retirement behaviour.

The paper shows that a constructed proxy variable of this type can explain transitions between economic activity and inactivity in a reduced form model that incorporates other time-varying covariates. Moreover, the approach seems superior, in terms of explanatory power, to the application of disability index-type health measures. The paper tested for symmetry in labour market transitions to changes in health, using 
predictions on an alternative subjective measure of ill health. Some evidence of asymmetry was found. No systematic differences were found in the response of men and women to changes in the health stock.

The final section briefly considered the reform to the public disability insurance programme in 1995, which both tightened formal eligibility conditions for disability insurance and also reduced the economic incentives to retire via the disability insurance 'route'. No significant effects were found. The failure to find a significant effect may reflect the possibility that there indeed was no effect (a result that is not incompatible with the aggregate data). Alternatively, it may reflect the weakness of the test in a reduced form framework that aggregates different retirement 'routes' into a single transition. This therefore suggests a strategy for future work - to identify separately the economic incentives attached to different retirement 'routes' in the UK (broadening the work of Blundell, Meghir and Smith, 2002) and to estimate a model that allows for greater choice of exit. It would also be useful to follow the path pursued by others, such as Kerkhof et al (1999), in handling the endogeneity of health status, and also in examining the impact of health status on the utility derived from different retirement routes - for example, the impact of health changes on prospective wages.

\section{References}

Anderson, K.H., Burkhauser, R. and Quinn, J.F. (1986) 'Do retirement dreams come true? The effect of unanticipated events on retirement plans', Industrial and Labor Relations Review, 39 , July, 518-526.

Banks, J., Blundell, R., Disney, R. and Emmerson, C. (2002) 'Retirement, pensions and the adequacy of saving: A guide to the debate', Institute for Fiscal Studies Briefing Note 29, London.

Blundell, R. and Johnson, P. (1998) 'Pensions and labour market participation in the UK', American Economic Review, 88, May, 168-172.

Blundell, R., Meghir, C., and Smith, S. (2002) 'Pension incentives and the pattern of early retirement', Economic Journal, 112, March, C153-C170.

Bound, J. (1991) 'Self-reported versus objective measures of health in retirement models', Journal of Human Resources, 26, 106-138.

Bound, J. and Burkhauser, R. (1999) 'Economic analysis of transfer programs targeted on people with disabilities', in O. Ashenfelter and D. Card (eds) Handbook of Labor Economics Volume 3C, Amsterdam: Elsevier Science, 3417-3528.

Bound, J., Schoenbaum, M., Stinebrickner, T.R. and Waidmann, T. (1999) 'The dynamic effects of health on the labor force transitions of older workers', Labour Economics, 6, 179-202.

Chamberlain, G. (1980) 'Analysis of covariance with qualitative data', Review of Economic Studies, 47, 225-238. 
Contoyannis, P. and Rice, N. (2001) 'The impact of health on wages: Evidence from the British Household Panel Survey', Empirical Economics, 26, 599-622.

Disney, R., Emmerson, C., Smith, S. and Smith, Z. (2003, forthcoming) Disability Benefits: A Tale of Two Reforms, mimeo, Institute for Fiscal Studies, London.

Disney, R., Grundy, E. and Johnson, P. (1997) The Dynamics of Retirement, Research Report No. 72, Department of Social Security, HMSO: London.

Disney, R. and Smith, S. (2002) 'The labour supply effect of the abolition of the earnings rule for older workers in the United Kingdom', Economic Journal, 112, March, C136-C152.

Disney, R. and Webb, S. (1991) 'Why are there so many long term sick in Britain?' Economic Journal, 101, March, 252-262.

Greene, W.H. (2000) Econometric Analysis, 4th edition, Prentice Hall: London.

Griliches, Z. (1974) 'Errors in variables and other unobservables', Econometrica, 42, November, 971-998.

Kaplan, G. and Camacho, T. (1983) 'Perceived health and mortality: A nine-year follow-up of the human population laboratory cohort', American Journal of Epidemiology, 117, 292-304.

Kerkhofs, M., Lindeboom, M. and Theeuwes,, J. (1999) 'Retirement, financial incentives and health', Labour Economics, 6, 203-227.

Lazear, E. (1986) 'Retirement from the labor force', 305-355 in O. Ashenfelter and R. Layard (eds) Handbook of Labour Economics, Volume 1, Elsevier Science Publishers, BV, Amsterdam.

Meghir, C. and Whitehouse, E. (1997) 'Labour market transitions and retirement of men in the UK', Journal of Econometrics, 79, 327-354.

Miniaci, R. and Stancanelli, E. (1998) 'Microeconometric analysis of the retirement decision: United Kingdom', OECD Economics Department Working Papers No. 206, Paris.

Myers, R.J. (1982) 'Why do people retire early from work?', Aging and Work, 5, 83-91.

Quinn, J.F., Burkhauser, R. and Myers, D.A. (1990) Passing the Torch: The influence of economic incentives on work and retirement, W.E. Upjohn Institute for Employment Research, Kalamazoo, Michigan.

Stern, S. (1989) 'Measuring the effect of disability on labor force participation', Journal of Human Resources, 24, Summer, 361-395.

Tanner, S. (1998) 'The dynamics of male retirement behaviour', Fiscal Studies, 19, May, 175-196.

Wannamethe, L. and Shaper, A.G. (1991) 'Self-assessment of health status and mortality in middle-aged British men', International Journal of Epidemiology, 20, 239-245.

Wooldridge, M. (2002) Econometric Analysis of Cross Section and Panel Data, MIT Press: Cambridge, Mass.

Zabalaza, A., Pissarides, C. and Barton, M. (1980) 'Social security and the choice between fulltime work, part-time work, and retirement', Journal of Public Economics, 14, 245-276. 
Table 1:

Self-assessed health, relative to cohort, 1991 and 1998

\begin{tabular}{l|cccc}
\hline & $\begin{array}{c}\text { Percentage of whole sample } \\
\text { reporting relative health } \\
\text { status as: }\end{array}$ & $\begin{array}{c}\text { Percentage of sample } \\
\text { present in 1991 and 1998 } \\
\text { reporting relative health } \\
\text { status as: }\end{array}$ \\
\hline Excellent & 1991 & 1998 & 1991 & 1998 \\
Good & 26.5 & 16.4 & 27.4 & 17.0 \\
Fair & 44.3 & 46.7 & 44.7 & 45.8 \\
Poor & 19.0 & 24.7 & 19.4 & 25.2 \\
Very poor & 7.7 & 9.4 & 6.3 & 9.2 \\
& 2.6 & 2.8 & 2.2 & 2.9 \\
No. of observations & 1,712 & 1,253 & 1,137 & 1,137 \\
\hline
\end{tabular}

Source: constructed by the authors from successive waves of the BHPS 
Table 2: Results of 1991 Ordered Probit estimating self-reported health status as a function of 'objective' health measures and individual characteristics

\begin{tabular}{|c|c|c|c|c|c|}
\hline Variable & Mean & s. deviation & Coefficient & & Standard error \\
\hline Male & 0.472 & 0.499 & -0.005 & & 0.058 \\
\hline In a couple & 0.771 & 0.420 & 0.141 & $* *$ & 0.071 \\
\hline Age/10 & 5.998 & 0.493 & -55.152 & & 43.652 \\
\hline (Age/10) squared & 36.218 & 5.932 & 9.436 & & 7.693 \\
\hline (Age/10) cubed & 220.157 & 53.910 & -0.534 & & 0.451 \\
\hline Owner-occupier & 0.776 & 0.417 & -0.070 & & 0.080 \\
\hline Own-outright & 0.486 & 0.500 & 0.049 & & 0.067 \\
\hline Housing equity ( $(, ` 000)$ & 54.628 & 74.907 & 0.001 & $* *$ & 0.000 \\
\hline Regional unemployment rate, $\%$ & 7.421 & 2.031 & -0.081 & & 0.075 \\
\hline White & 0.976 & 0.154 & 0.013 & & 0.170 \\
\hline Number of children in household & 0.063 & 0.320 & -0.106 & & 0.078 \\
\hline Regional dummies: & & & & & \\
\hline Live in conurbation & 0.290 & 0.454 & 0.059 & & 0.094 \\
\hline South West & 0.102 & 0.303 & 0.067 & & 0.113 \\
\hline East Midlands & 0.078 & 0.268 & 0.032 & & 0.139 \\
\hline West Midlands & 0.096 & 0.294 & 0.128 & & 0.151 \\
\hline North West & 0.107 & 0.309 & 0.303 & & 0.239 \\
\hline Yorkshire/Humberside & 0.087 & 0.282 & 0.150 & & 0.197 \\
\hline Rest of North & 0.060 & 0.238 & 0.306 & & 0.326 \\
\hline Wales & 0.059 & 0.235 & 0.145 & & 0.248 \\
\hline Scotland & 0.077 & 0.267 & 0.279 & & 0.264 \\
\hline Education dummies: & & & & & \\
\hline A-level (or equivalent) & 0.074 & 0.262 & -0.185 & & 0.119 \\
\hline O-level (or equivalent) & 0.131 & 0.337 & -0.084 & & 0.100 \\
\hline Low education & 0.104 & 0.305 & -0.123 & & 0.108 \\
\hline No qualifications & 0.476 & 0.499 & -0.357 & $* * *$ & 0.078 \\
\hline Health 'difficulties': & & & & & \\
\hline Doing housework & 0.071 & 0.257 & -0.659 & $* * *$ & 0.156 \\
\hline Climbing stairs & 0.091 & 0.287 & -0.369 & $* *$ & 0.155 \\
\hline Getting dressed & 0.024 & 0.153 & -0.378 & & 0.221 \\
\hline Walking $10 \mathrm{mins}$ & 0.090 & 0.286 & -0.762 & $* * *$ & 0.149 \\
\hline Registered disabled & 0.073 & 0.261 & -0.128 & & 0.134 \\
\hline Health 'problems': & & & & & \\
\hline Arms/legs/hands & 0.403 & 0.491 & -0.554 & $* * *$ & 0.061 \\
\hline Sight & 0.058 & 0.235 & -0.374 & $* * *$ & 0.099 \\
\hline Hearing & 0.120 & 0.325 & 0.027 & & 0.095 \\
\hline Skin/allergies & 0.089 & 0.285 & -0.219 & $* *$ & 0.101 \\
\hline Chest/breathing & 0.133 & 0.339 & -0.926 & $* * *$ & 0.093 \\
\hline Heart/blood press. & 0.245 & 0.430 & -0.693 & $* * *$ & 0.071 \\
\hline Stomach/digestion & 0.084 & 0.277 & -0.544 & $* * *$ & 0.110 \\
\hline Diabetes & 0.043 & 0.202 & -0.933 & $* * *$ & 0.163 \\
\hline Anxiety/depression & 0.073 & 0.261 & -0.656 & $* * *$ & 0.118 \\
\hline Alcohol/drugs & 0.003 & 0.058 & -0.957 & $* *$ & 0.399 \\
\hline Epilepsy & 0.007 & 0.086 & -0.662 & $* *$ & 0.308 \\
\hline Migraine & 0.076 & 0.264 & -0.464 & $* * *$ & 0.104 \\
\hline Other & 0.054 & 0.227 & -0.632 & $* * *$ & 0.120 \\
\hline F-tests: & & & Chi-Squared & & P-Value \\
\hline Regional dummies & & & 2.83 & & 0.971 \\
\hline Education dummies & & & 25.90 & $* * *$ & 0.000 \\
\hline Health 'difficulties' & & & 151.06 & $* * *$ & 0.000 \\
\hline Health 'problems' & & & 405.66 & $* * *$ & 0.000 \\
\hline
\end{tabular}

**: significant at $5 \%$ level

$* * *$ : significant at $1 \%$ level

Number of obs $=1,712 ; \log$ likelihood $=-1,774.5939 ; \operatorname{LR} \chi^{2}(42)=965.75$

A full set of results from the other 7 years is available from the authors on request. 
Table 3:

Economic activity equations

\begin{tabular}{|c|c|c|c|c|c|c|}
\hline & \multicolumn{2}{|c|}{$\begin{array}{c}(1) \\
\text { Fixed effects logit }\end{array}$} & \multicolumn{2}{|c|}{$\begin{array}{l}(2) \\
\text { Logit }\end{array}$} & \multicolumn{2}{|c|}{$\begin{array}{c}(3) \\
\text { Linear fixed effects }\end{array}$} \\
\hline & Coeff. & s.e. & Coeff. & s.e. & Coeff. & s.e. \\
\hline Age/10 & $206.366^{* * *}$ & 69.084 & $51.954 * *$ & 20.882 & $15.097 * * *$ & 3.361 \\
\hline (Age/10) squared & $-34.913^{* * *}$ & 11.546 & $-8.475^{* *}$ & 3.511 & $-2.578^{* * *}$ & 0.558 \\
\hline (Age/10) cubed & $1.903^{* * *}$ & 0.640 & $0.441 * *$ & 0.196 & $0.142^{* * *}$ & 0.031 \\
\hline State pension age & $-0.788^{* * *}$ & 0.268 & $-0.173^{* *}$ & 0.084 & $-0.085^{* * *}$ & 0.018 \\
\hline Couple & -0.654 & 0.568 & $0.288^{* * *}$ & 0.059 & -0.036 & 0.031 \\
\hline Regional unemployment rate & $-0.088^{* *}$ & 0.038 & -0.006 & 0.014 & $-0.005^{* *}$ & 0.002 \\
\hline Own-outright & -0.387 & 0.275 & $-0.459 * * *$ & 0.058 & $-0.073^{* * *}$ & 0.020 \\
\hline Health stock & $0.279 * * *$ & 0.105 & $0.752^{* * *}$ & 0.031 & $0.035^{* * *}$ & 0.007 \\
\hline Constant & $\mathrm{n} / \mathrm{a}$ & $\mathrm{n} / \mathrm{a}$ & $-102.052^{* * *}$ & 38.666 & $-27.993 * * *$ & 6.702 \\
\hline No of cases & $\mathrm{Obs}=4,348$ & Groups $=617$ & Obs $=11,152$ & & $\begin{array}{l}\text { Obs }=11,152 \\
\mathrm{R}^{2} \text { within } 0 .\end{array}$ & ups $=1,945$ \\
\hline Log likelihood & $-1,109.98$ & & $-6,030.07$ & & $\begin{array}{ll}\text { Between } & 0 . \\
\text { Overall } & 0.2\end{array}$ & \\
\hline
\end{tabular}

Note: $* * *=$ significant at $1 \%$ level $* *=$ significant at $5 \%$ level $*=$ significant at $10 \%$ level.

The standard logit model also includes a set of regressors that are time-invariant, such as gender, educational qualifications and regional dummies, which are not included in either the conditional logit or the linear fixed effects model. These comprise all of the variables show in table 2 except for those relating to health difficulties, health problems and whether an individual is registered disabled (since they form the vector $Z_{i t}$ in equation 1 in section 2.1).

Due to the health stock being calculated from the predicted index of eight ordered probits the standard errors are estimated using a bootstrapping technique. 1,500 bootstraps for each equation have been run. In the conditional logit and the linear fixed effects model we select a random sample of individuals (and then select all observations for that individual), while in the logit model we select randomly across all observations (i.e. observations of the same individual in different years are selected separately). Due to some of the random draws leading to nonconvergence of the ordered probits the total number of bootstraps used in the calculation of the standard errors varies from 1,409 in the conditional logit and the linear fixed effects model to 1,390 in the standard logit. 
Table 4:

Economic activity equations

(Alternative health question)

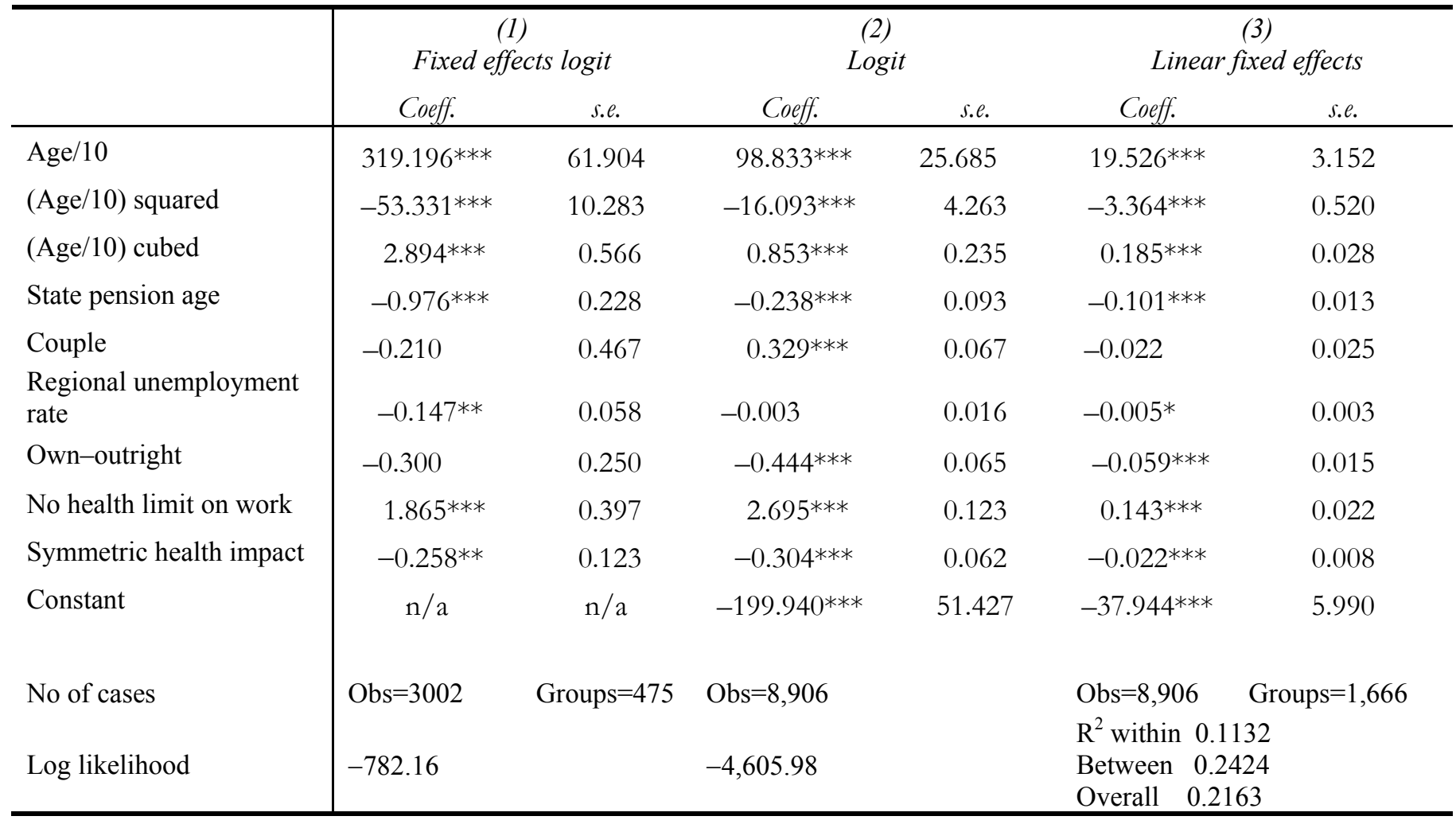

Note: $* * *=$ significant at $1 \%$ level $* *=$ significant at $5 \%$ level $*=$ significant at $10 \%$ level.

The IV-type technique is applied to the question: 'Does your health affect the type or amount of work that you undertake?' [YES/NO]

As in Table 3, standard errors are estimated using a bootstrapping technique. 1,500 bootstraps for each equation have been run. All random draws converged as the $1^{\text {st }}$ stage estimation is a probit as opposed to the ordered probit used in table 3. 
Table 5

Sensitivity of economic activity to health measure

\begin{tabular}{|c|c|c|c|c|}
\hline Specification & $\begin{array}{c}(1) \\
\text { Coeff (se) }\end{array}$ & $\begin{array}{c}(2) \\
\text { Coeff (se) }\end{array}$ & $\begin{array}{c}\text { (3) } \\
\text { Coeff (se) }\end{array}$ & $\begin{array}{c}(4) \\
\text { Coeff (se) }\end{array}$ \\
\hline Predicted health stock & $0.28(0.11)$ & $\overline{-}$ & $\overline{-}$ & - \\
\hline No of difficulties: & - & $-0.44(0.12)$ & & \\
\hline Doing housework & & & $-0.49(0.31)$ & - \\
\hline Climbing stairs & & & $0.11(0.31)$ & - \\
\hline Getting dressed & & & $-1.12(0.61)$ & $-1.35(0.59)$ \\
\hline Walking 10mins & & & $-0.77(0.32)$ & $-0.84(0.29)$ \\
\hline Registered disabled & - & $-1.57(0.46)$ & $-1.67(0.47)$ & $-1.79(0.47)$ \\
\hline No of health problems: & - & $-0.05(0.06)$ & $-0.06(0.13)$ & - \\
\hline Arms/legs/hands & & $-0.00(0.00)$ & $0.13(0.24)$ & - \\
\hline $\begin{array}{l}\text { Sight } \\
\text { Hearino }\end{array}$ & & & $-0.36(0.24)$ & - \\
\hline Skin/allergies & & & $0.12(0.24)$ & - \\
\hline Chest/breathing & & & $0.12(0.23)$ & - \\
\hline Heart/blood press. & & & $\begin{array}{l}-0.39(0.19) \\
-024(023)\end{array}$ & - \\
\hline Stomach/digestion & & & $\begin{array}{r}-0.24(0.23) \\
1.99(0.50)\end{array}$ & $1.88(0.49)$ \\
\hline $\begin{array}{l}\text { Diabetes } \\
\text { Anxietv/depression }\end{array}$ & & & $-0.44(0.24)$ & - \\
\hline Alcohol/drugs & & & $0.14(1.00)$ & - \\
\hline Epilepsy & & & $0.44(1.80)$ & - \\
\hline Migraine & & & $0.41(0.24)$ & - \\
\hline Other & & & $0.28(0.24)$ & - \\
\hline Log likelihood & $-1,109.98$ & $-1,095.91$ & $-1,079.19$ & $-1,088.69$ \\
\hline
\end{tabular}

Note: Coefficients are illustrated for the fixed effect logit. 
Table 6:

Economic Activity equations pre- and post-1995 reform (selected coefficients)

\begin{tabular}{|c|c|c|c|c|c|}
\hline & \multicolumn{2}{|c|}{$\begin{array}{c}\text { (1) } \\
\text { Fixed effects logit }\end{array}$} & \multicolumn{3}{|c|}{$\begin{array}{c}\text { (3) } \\
\text { Linear fixed effects }\end{array}$} \\
\hline & Coeff. & s.e. & Coeff. & & s.e. \\
\hline State pension age & $-0.67 * *$ & 0.28 & $-0.08^{* *}$ & 0.02 & \\
\hline Health stock & $0.26^{* *}$ & 0.11 & $0.03 * *$ & 0.01 & \\
\hline Eligible ICB & 0.27 & 0.21 & 0.01 & 0.02 & \\
\hline Hstock*eligible ICB & 0.10 & 0.20 & 0.01 & 0.01 & \\
\hline Log likelihood & $\begin{array}{l}\text { Test to } \\
\chi^{2}(2)=2\end{array}$ & $\begin{array}{l}8.62 \\
\text { de ICB vars: } \\
o b>\chi^{2}=0.26\end{array}$ & $\begin{array}{c}\mathrm{R}^{2} \text { within } \\
\text { between } \\
\text { overall }\end{array}$ & $\begin{array}{c}0.1288 \\
0.2125 \\
0.2023\end{array}$ & \\
\hline
\end{tabular}

Note: $* *=$ significant at $5 \%$ level

As in Table 3, standard errors are estimated using a bootstrapping technique. 1,500 bootstraps for each equation have been run. Due to some of the random draws leading to non-convergence of the ordered probits the total number of bootstraps used in the calculation of the standard errors varies from 1,397 in the conditional logit and the linear fixed effects model to 1,387 in the standard logit.

Figure 1

Numbers of claimants of Invalidity and Incapacity Benefit aged 50 and over, 1980 to 2000

Men

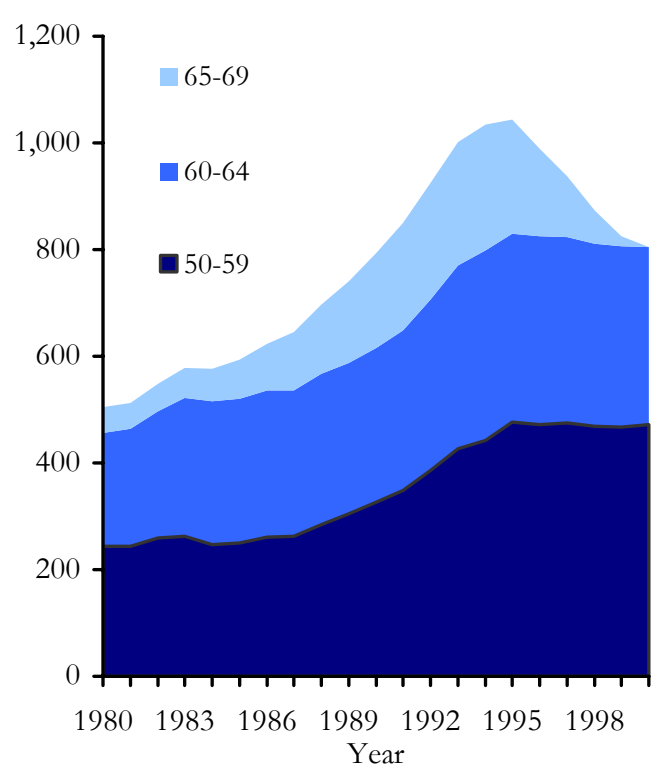

Women

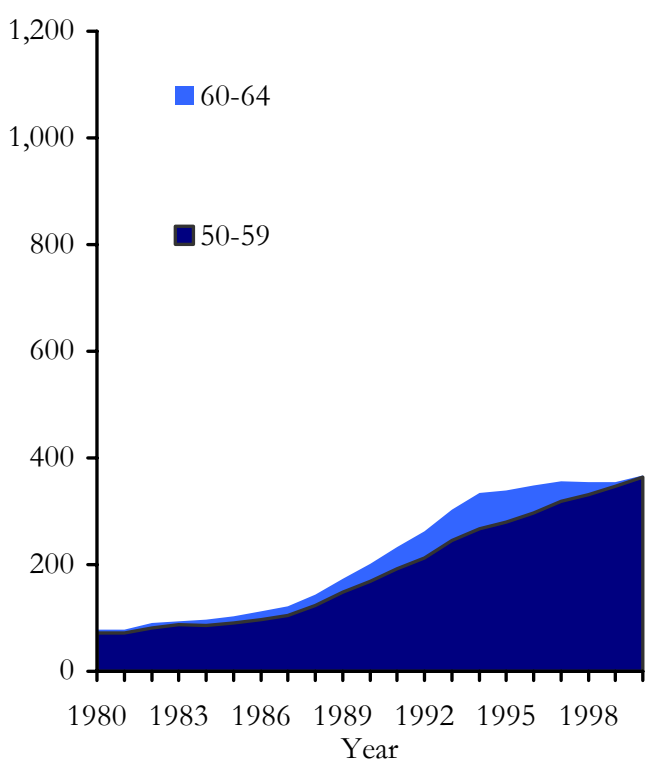

Source: Banks et al (2002) 


\section{Appendix}

Descriptive statistics for constructed health stock variable

\begin{tabular}{|l|ccc|cr|}
\hline Variable & $\begin{array}{c}\mathbf{2 5}^{\text {th }} \\
\text { percentile }\end{array}$ & Median & $\begin{array}{c}\mathbf{7 5}^{\text {th }} \\
\text { percentile }\end{array}$ & Mean & (s. d.) \\
\hline Health stock, those in work & -0.157 & 0.319 & 0.701 & 0.190 & $(0.695)$ \\
Health stock, those not in work & -0.341 & 0.225 & 0.663 & 0.027 & $(0.886)$ \\
Health stock, all in baseline & -0.248 & 0.270 & 0.681 & 0.108 & $(0.801)$ \\
& & & & & \\
Change in health stock & -0.291 & -0.005 & 0.257 & -0.027 & $(0.555)$ \\
Difference between maximum & 0.679 & 0.992 & 1.391 & 1.100 & $(0.637)$ \\
and minimum health stock & & & & & \\
\hline
\end{tabular}

These 'stocks' are measured for the 617 individuals that make up the sample for our "baseline" fixed effects logit model. This gives 4,348 person year observations (2,148 for people who are in work and 2,200 for those who are out of work) and 3,558 observed first differences.

Whilst our health stock variable is constructed to be mean zero across all person year observation in our full sample, we see that in the subset of the data that are used for estimating the fixed effects logit model the mean is slightly positive: the tail of unhealthy people who are dropped because they never work have health stocks that are sufficiently bad (on average) to more than offset the fact that some healthy people are dropped from the fixed effects logit because they work in every period.

These data show that it is uncommon for the measured health stock of an individual to change by as much as one unit between one year and the next: 8 per cent (289 observations) of the year-on-year changes that we observe are of one unit of more in either direction (of these, 170 are declines and 119 are increases).

However, as the median in the last row of the table indicates, almost half (actually 49 per cent or 303 people) of the people in this sample have a maximum measured health stock that is one unit or more greater than their minimum measured health stock across all years. 